buted to legal therapeutic abortions in 1969, not including 4 registered under the Act as resulting from legal operations after illegal or spontaneous abortions. In addition, 8 deaths "from other underlying causes after legal abortion operations" were registered under the Act. Of the latter, 4 resulted from conditions (congenital heart disease; cancer of rectum; cerebral haemorrhago; acute myocarditis) which were probably the reasons for, rather than the results of, the abortion operations. But the other 4 (3 pulmonary embolisms; 1 respiratory obstruction whilo recovering from anaesthetic) seem themselves more or less directly attributable to the operation, in the sense that these deaths probably would not have occurred had the pregnancies not, been terminatcd. $S$, there were certainly 10 deaths, and probably 14, resulting from legal abortions in 1969.

Also "a further 25 deaths were classified as directly due to abortions other than under the Act" so that the total for all abortions (legal, illogal and spontaneous) was certainly 35 and probably up to 39 in 1969 , as compared with 34 for 1967. It is true that 1967 seems to have been a good yoar, since the Registrar General recorded 53 abortion deaths for 1966, and 50 for the transitional year 1968 (4 months under the old law and 8 under the new); but plainly there is here as yet no good evidence of any dramatic reduction in mortality resulting from the Abortion Act 1967, as has sometimes becn claimed. Yours faithfully.

Conville and Caius College,

C. B. CoOdhart

Cambridge.

${ }^{1}$ Crossman, R., Hansard (Commons), written answers, col. 560 (May 28, 1970). ${ }^{2}$ Crossman, R., Hansard (Commons), written answers, col. 272 (March 23, 1970).

\section{Blue Streak's Record}

Sir,- T should be interested to knuw by what criterion you judgo Blue Streak to be "unreliable" as the first stage of the Europa launcher (Nature, 227. 425; 1970). Ten successful firings out of ten secms to me to deserve a slightly kinder description.

\section{Yours faithfully:}

R. H. W. B̈TLLOCK

Ministry of Technology,

Prospect House,

100 New ()xford Street, London WCI.

Mr Bullock is right. Blue Streak is reliable. But there is nothing to modify the assertion in the leading article that it is otherwise unsuitable as a starting point for a comprehensive European space programme.-.Editor, Nature.

\title{
Obituaries
}

\section{Professor F. T. von Brücke}

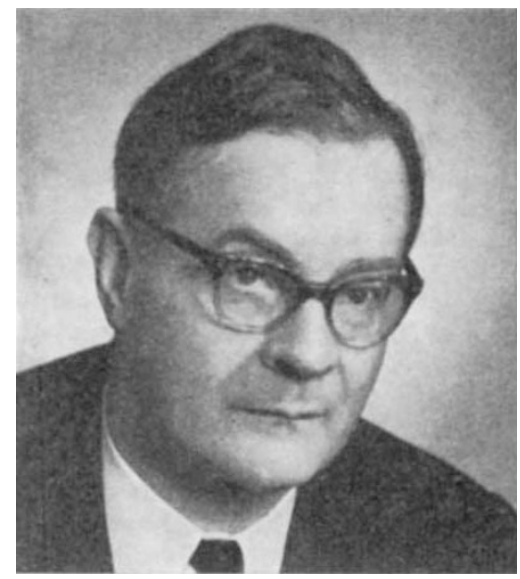

Franz Theodor von Brücke, professor of pharmacology and toxicology at the University of Vienna, died on March 24, 1970, at the age of 62 , after a short illness.

Brücke's capability for independent research was soon apparent from a paper on the epiphyseal cartilage of long bones which he published while he was a medical student. His later development was profoundly influenced by such distinguished teachers as Otto Loewi and H. H. Dale, under whose guidance he gained experience in the pharmacology of the central and peripheral autonomic nervous system, an area of research to which he devoted the greater part of his life. It was therefore no accident that he was drawn to the Vienna school of pharmacologists, pioneered by H. H. Mcyer and his successor's, E. P. Pick and R. Rössler, whom he followed to the chair in 1948.

As early as 1935, Brücke recognized the antagonism of bulbocapnine to some of the central effects of apomorphine, an interesting observation in view of the now established interrelationship between dopamine, apomorphine and bulbocapnine. This led later to studies on the different patterns of release of epinephrine from the adrenal medulla after electrical stimulation of the hypothalamus and occlusion of the carotid sinus. An observation of far-reaching theoretical importance was that small amounts of acetylcholine, injected into the skin, elicited a pilomotor response, whereas larger amounts abolished the effect of sympathetic stimulation.

Brücke investigated the effect of denervation of the superior cervical ganglion of the eat as manifested in its sensitivity to adrenaline and acetylcholine and in cholinesterase depletion. Investigations into the innervation of the rabbit cardia led him to postulate the presence of adrenergic fibres in the vagus and cholinergic fibres in the splanchnic nerve. The induction of spasm of the rabbit cardia following severance of the vagus proved to be a simple device for the evaluation of spasmolytic agents. Brücke also studied the influence of acidity and basicity on the cardiac glycosides and described the importance of the binding of digitoxin to protein.

With the increase in his administrative responsibilities as chairman of a large research and teaching department, Brücke's own involvement in laboratory work decreased in later years, but he continued to stimulate research among his students and co-workers. His ability to generate enthusiasm attracted talented young investigators who have since taken up important academic positions in Europe, the USA and Canada. Under Brücke's direction the Vienna school cmbarked on a broad investigation of dicholinesters of dicarboxylic acids as muscle relaxants which led to the introduction of succinyldicholine into anresthesiology. Another line of inquiry initiated by Brücke was the investigation by electroencephalography of hippocampal activity in the rabbit.

Brücke was recognized as an outstanding authority in matters of public health and in his capacity as an adviser to the pharmaceutical industry. His editorship of the Wiener Klinische Wochenschrift won for the journal a high reputation; his communications, both oral and written, sparkled with lucidity and wit. It is no exaggeration to say, too, that his acumen and foresight spared his country the ravages of thalidomide. 